\title{
Cross-Cultural Adaptation and Validation of the European Portuguese Version of the Western Ontario Shoulder Instability Index (WOSI)
}

\author{
Adaptação Cultural e Validação da Versão Portuguesa do \\ Western Ontario Shoulder Instability Index (WOSI)
}

\author{
Rui Manuel TORRES $\square^{1,2}$, Sara Isabel FARIA3 ${ }^{3}$, Luís Manuel CAVALHEIRO ${ }^{4,5}$, Pedro LOPES FERREIRA ${ }^{5,6}$, \\ Rui SOLES GONÇALVES ${ }^{4,5}$ \\ Acta Med Port 2022 Jul-Aug;35(7-8):522-528 - https://doi.org/10.20344/amp.15119
}

\section{ABSTRACT}

Introduction: The Western Ontario Shoulder Instability Index (WOSI) is a self-administered questionnaire specifically used to determine the impact of shoulder instability on quality of life. The aim of this study was to translate the WOSI into European Portuguese and analyze its validity and reliability in a population with shoulder instability.

Material and Methods: The WOSI was translated and culturally adapted from its original version into European Portuguese (WOSIPT). Internal consistency and test-retest analyses were conducted to determine the level of reliability of the scale. WOSI-PT, QuickDASH, and SF-12 questionnaires were applied to 81 patients with symptomatic shoulder instability to assess validity, and reliability was tested by randomly selecting 50 patients within 72 hours using a test-retest design.

Results: The reliability of the WOSI-PT was very high, with Cronbach's alpha equal to 0.97 and an intraclass correlation coefficient of 0.98 . Regarding the construct validity, the correlation between the WOSI-PT and QuickDASH was high and negative (-0.79). The correlations between WOSI-PT and SF-12 were positive, respectively, moderate with physical $(0.66)$ and low with mental (0.34) health. Conclusion: WOSI-PT is a reliable and valid instrument for assessing the functional impact of shoulder joint instability on quality of life. Keywords: Cross-Cultural Comparison; Patient Outcome Assessment; Portugal; Quality of Life; Shoulder Dislocation; Shoulder Joint; Surveys and Questionnaires; Translations

\section{RESUMO}

Introdução: O Western Ontario Shoulder Instability Index (WOSI) é um questionário de autopreenchimento utilizado especificamente para determinar o impacto da instabilidade do ombro na qualidade de vida. O objetivo deste estudo foi traduzir o WOSI para português e analisar a sua validade e fiabilidade para a população portuguesa com instabilidade do ombro.

Material e Métodos: O WOSI foi traduzido e adaptado culturalmente da sua versão original para Português (WOSI-PT). Foram efetuadas as análises de consistência interna e teste-reteste para determinar o seu nível de fiabilidade. Os questionários WOSI-PT, QuickDASH, and SF-12 foram aplicados a 81 pacientes com sintomas de instabilidade para avaliar a validade, enquanto a fiabilidade foi testada usando 50 desses pacientes selecionados de modo aleatório, num estudo do tipo teste-reteste com 72 horas de intervalo. Resultados: A fiabilidade do WOSI-PT foi excelente com alfa de Cronbach de 0,97 e um intraclass correlation coeficiente de 0.98. Relativamente à validade de constructo, a correlação entre o WOSI-PT e a QuickDASH foi alta e negativa $(-0,79)$. A correlação entre o WOSI-PT e o SF-12 foi positiva e moderada para a componente física $(0,66)$ e positiva e baixa para a componente de saúde mental $(0,34)$.

Conclusão: O WOSI-PT é um instrumento fiável e válido para avaliar o impacto da instabilidade do ombro na qualidade de vida.

Palavras-chave: Articulação do Ombro; Avaliação de Resultados da Assistência ao Paciente; Comparação Transcultural; Inquéritos e Questionários; Luxação do Ombro; Portugal; Qualidade de Vida; Traduções

\section{INTRODUCTION}

Shoulder instability can be described as the inability to maintain the correct positioning of the humeral head in the scapular glenoid cavity during functional movements of the upper limb. This disability usually causes pain or discomfort and has an incidence of about $2 \%$ in the general population. ${ }^{1}$ Shoulder instability may be classified as anterior, posterior, or multidirectional, and it may have a traumatic or non-traumatic origin. However, anterior traumatic instability is the most commonly described origin, and is predominant in middle and senior age individuals. ${ }^{2}$
The stability of the glenohumeral joint depends on the interaction of both static and dynamic-stabilizing structures. Static stabilizers include the bony anatomy, negative intraarticular pressure, the glenoid labrum, and the glenohumeral ligaments along with the joint capsule. The dynamicstabilizing structures comprise the rotator cuff muscles and the other muscular structures surrounding the shoulder joint. The combined effect of these stabilizers is to support multiple degrees of motion within the glenohumeral joint. ${ }^{3}$

Several extrinsic risk factors are well described in

1. Department of Physiotherapy. CESPU. North Polytechnic Institute of Health. Paredes. Portugal.

2. Department of Physiotherapy. Center for Rehabilitation Research. Polytechnic Institute of Oporto. Oporto. Portugal.

3. Department of Physiotherapy. School of Health. Polytechnic Institute of Oporto. Oporto. Portugal.

4. Department of Physiotherapy. Coimbra Health School. Polytechnic Institute of Coimbra. Coimbra. Portugal.

5. Centre for Health Studies and Research. University of Coimbra. Coimbra. Portugal.

6. Faculty of Economics. University of Coimbra. Coimbra. Coimbra. Portugal.

$\triangle$ Autor correspondente: Rui Manuel Torres. rui.torres@ipsn.cespu.pt

Recebido/Received: 20/10/2020 - Aceite/Accepted: 13/10/2021 - Publicado Online/Published Online: 18/02/2022 - Publicado/Published: 01/07/2022 Copyright $\odot$ Ordem dos Médicos 2022 
shoulder instability, namely, those related to work or activity using the upper limbs above the head, impact sports, either in direct contact with other athletes or on the playing field, and intrinsic factors such as age and hypermobility of the joint complex. ${ }^{2}$

Traumatic dislocation of the glenohumeral joint is the most common injury among young athletes. ${ }^{4}$ In fact, traumatic shoulder instability, such as subluxation and dislocation, is commonly associated with rugby players and wrestlers due to collisions between athletes, while instability resulting from repetitive microtrauma is usually associated with tennis, baseball, and volleyball players, as well as swimmers. ${ }^{5}$ Nevertheless, this problem may also be jobrelated, such as painters and decorators or carpenters.

According to Perrin et $a l,{ }^{6}$ the subjective symptoms that predominate in shoulder instability are apprehension and lack of confidence to perform activities of daily living and sports. ${ }^{7}$ These subjective symptoms lead to a decrease in participation in activities by patients, resulting in a negative impact on their quality of life. ${ }^{6}$ Therefore, subjective clinical evaluation methods are important when used along with physical examination, having in mind the patient's opinion about his or her condition. ${ }^{8}$ Moreover, these methods could provide relevant information about function and quality of life. ${ }^{3}$

However, instruments validated for the Portuguese population, such as the Shoulder Pain and Disability Index (SPADI) ${ }^{9}$ and the Disabilities of the Arm, Shoulder and Hand (DASH), ${ }^{10}$ aim essentially to measure the function and pain scores. ${ }^{6}$ Furthermore, the DASH is not a shoulder-specific instrument, i.e., it is a tool to assess disabilities of the arm, shoulder, and hand.

The Western Ontario Shoulder Instability Index (WOSI), developed by Kirkley et al, ${ }^{11}$ is a simple questionnaire designed for self-assessment of shoulder function in patients with instability problems and the impact of the condition on quality of life, and it has been suggested as being more effective due to its responsiveness. ${ }^{12}$ It is also claimed to be one of the best self-reported measurement methods for patients with shoulder joint dysfunction. ${ }^{13}$

The WOSI aims to measure functionality and the impact of shoulder instability on quality of life. In comparison with the aforementioned questionnaires, WOSI is a more specific shoulder instability questionnaire as it contains twentyone questions across four domains. The first domain contains 10 items on 'physical symptoms'; the second domain consists of four items directed to 'sports, recreational activities and work'; the third domain has four items related with 'lifestyle'; and finally, the fourth domain has three items on 'emotions'. Each item can be scored from 0 to 100 on the Visual Analog Scale. Thus, according to the authors of the original version, the results from the questionnaire range from 0 to 2100, where 0 means that the patient has 'no decrease in quality of life' relative to shoulder symptomatology, and 2100 means the patient has an extreme decrease in quality of life related with shoulder symptoms. However, a score ranging from 0 (worst) to 100 (best) was used to be comparable with other instruments, as the Short Form 36. ${ }^{14}$

Knowing that WOSI had not yet been validated for the Portuguese population, the aim of this work was to translate the WOSI into European Portuguese, to culturally adapt it, and to verify its reliability and validity.

\section{MATERIAL AND METHODS}

Permission to develop the Portuguese version of WOSI was obtained from the authors, who provided the original version. The study was approved by the Ethics Committee of the School of Health of the Polytechnic Institute of Porto ( $n^{\circ}$ CE 0926).

\section{Cross-cultural adaptation}

The translation and cross-cultural adaptation process of the original WOSI questionnaire for the Portuguese population was performed according to the guidelines proposed by Reeve et $a l^{15}$ and Mokkink et al. ${ }^{16}$

Translation of the WOSI questionnaire was performed independently by two native Portuguese professional translators. Thus, two different versions of the questionnaire were obtained. The obtained translations were discussed in an initial consensus panel that was comprised of both translators and members of this research team study, and a consensus was reached on a Portuguese translation.

This version was back-translated to English by two independent English translators. The translation and backtranslations were compared by a second consensus panel composed of the last two translators and the same members of the research team who took part in the first panel.

In order to obtain a clinical perspective and to learn the most appropriate manner in which to communicate with Portuguese patients with shoulder instability, this last version was submitted to an orthopedic surgeon, an expert in shoulder assessment and surgery with over thirty years of experience in the field, and a physiotherapist with more than ten years of experience in shoulder rehabilitation.

Therefore, ten patients with shoulder instability completed the questionnaire, aiming to test its clarity, comprehension, and acceptability.

\section{Validation study}

\section{Patients}

The study was carried out with 103 patients with shoulder instability (anterior, posterior, multidirectional instability) who were selected from three local healthcare institutions. Twenty-two patients were later excluded as they did not meet the inclusion criteria or declined to participate in the study. The number of patients in the sample was determined following the recommendation of Altman, who states that the minimum number of patients must be 50 for methodological comparison. ${ }^{17}$ The inclusion criteria were as follows: (1) eighteen years old or older; (2) diagnosed with shoulder symptomatic instability, whether anterior, posterior, or multidirectional, traumatic or non-traumatic; (3) a native Portuguese speaker and able to read Portuguese; and (4) receiving no treatment between test-retest 
assessments. The exclusion criteria were as follows: (1) inability to complete the form due to significant psychiatric or psychological disorder; (2) having a neurological disease; (3) having systemic inflammatory conditions; and (4) having neoplastic disorders or cervical radiculopathy and thoracic outlet syndrome.

The study consisted of completing a questionnaire for demographic and disease characteristics, the WOSI-PT, the Quick Disabilities of the Arm, Shoulder and Hand Score (QuickDASH), and the Short Form 12 Health Survey (SF12) questionnaires. However, in order to determine test-retest reliability, 50 of the 81 patients were randomly selected to repeat the WOSI-PT 72 hours later. This period of time was defined with the aim of avoiding the "memory effect" and ensure that patients remained in a stable clinical condition.

For the validation process the following instruments were used:
The QuickDASH, developed by Beaton et a/18 and validated for the Portuguese population by the authors Santos and Gonçalves, aims to measure the impact of a health condition on upper limb function and to measure the impact of healthcare provided after upper limb injury. ${ }^{10}$

The SF-12 was developed by Ware et a/ ${ }^{19}$ and validated for the Portuguese population by Ferreira. ${ }^{20}$ This questionnaire aims to measure and evaluate the general health status of subjects with and without disease.

\section{Statistical analysis}

The non-normality of distribution of values was verified with the Shapiro-Wilk test. Therefore, quantitative variables were described using the median and interquartile range (IQR) values, whereas the categorical variables were presented by frequency and percentage values.

Test-retest reliability of the WOSI-PT was assessed by intraclass correlation coefficient (ICC) and internal consistency analysis using Cronbach's alpha. Standard

Table 1 - Demographics and baseline characteristics of patients

\begin{tabular}{|c|c|c|}
\hline Characteristics & $\begin{array}{l}\text { Total sample } \\
\quad(n=81)\end{array}$ & $\begin{array}{l}\text { Test-retest group } \\
\qquad(n=50)\end{array}$ \\
\hline \multicolumn{3}{|l|}{ Gender n (\%) } \\
\hline Male & $37(45.5)$ & $17(34.0)$ \\
\hline Female & $44(54.3)$ & $33(66.0)$ \\
\hline Age (years; $X \pm S D)$ & $37.3 \pm 17.6$ & $42.4 \pm 18.1$ \\
\hline Body Mass Index $\left(\mathrm{Kg} / \mathrm{m}^{2} ; \mathrm{X} \pm \mathrm{SD}\right)$ & $25.7 \pm 4.3$ & $26.7 \pm 4.7$ \\
\hline Average duration of complaints (months; $\mathrm{X} \pm \mathrm{SD}$ ) & $27.1 \pm 32.2$ & $31.4 \pm 35.4$ \\
\hline \multicolumn{3}{|l|}{ Handedness $\mathrm{n}(\%)$} \\
\hline Right & $74(91.4)$ & $46(92.0)$ \\
\hline Left & $7(8.6)$ & $4(8.0)$ \\
\hline \multicolumn{3}{|l|}{ Affected side $\mathrm{n}(\%)$} \\
\hline Dominant & $39(48.1)$ & $24(48.0)$ \\
\hline Non-dominant & $15(18.5)$ & $7(14.0)$ \\
\hline Both & $27(33.4)$ & $19(38.0)$ \\
\hline \multicolumn{3}{|l|}{ Type of Shoulder Problems n (\%) } \\
\hline Anterior Instability & $58(71.6)$ & $40(80.0)$ \\
\hline Posterior Instability & $2(2.5)$ & $1(2.0)$ \\
\hline Multidirectional instability & $21(25.9)$ & $9(18.0)$ \\
\hline \multicolumn{3}{|l|}{ Questionnaire Score (Median $\pm I Q R$ ) } \\
\hline WOSI total & $60.1 \pm 38.8$ & $49.8 \pm 27.9$ \\
\hline WOSI Physical symptoms & $61.0 \pm 28.3$ & $53.6 \pm 18.5$ \\
\hline WOSI Sports/recreation/work & $56.1 \pm 53.6$ & $39.9 \pm 27.4$ \\
\hline WOSI Lifestyle & $73.0 \pm 50.7$ & $51.9 \pm 40.9$ \\
\hline WOSI Emotional well-being & $49.6 \pm 41.7$ & $33.7 \pm 33.7$ \\
\hline QuickDASH Total & $31.8 \pm 34.1$ & $47.7 \pm 30.1$ \\
\hline QuickDASH Work & $43.7 \pm 43.7$ & $62.5 \pm 37.5$ \\
\hline QuickDASH Sports & $31.3 \pm 39.1$ & $43.7 \pm 31.3$ \\
\hline SF-12 Physical component & $39.6 \pm 14.4$ & $36.8 \pm 9.0$ \\
\hline SF-12 Mental component & $51.3 \pm 46.3$ & $46.1 \pm 16.7$ \\
\hline
\end{tabular}

Values of WOSI and QuickDASH are expressed as percentage; Values of SF-12 physical component range from 24.0 to 56.6 points; Values of SF-12 mental component range from 19.1 to 60.9 points 
measurement error (SEM) as well as minimal detectable change at the individual and group levels were calculated in the WOSI-PT total score and in all four domains. Regarding the sensitivity of the scale, floor and ceiling effect were measured.

For construct validity, three predefined analyses were performed: the correlations between WOSI-PT (and its domains) and QuickDASH total score, with QuickDASH modules and with SF-12.

The construct validity was analyzed using Spearman correlation, and the values were interpreted as follows: very high positive (or negative) correlation when greater than or equal to 0.90 ; high positive (or negative) correlation when between 0.70 to 0.89 ; moderate positive (or negative) when between 0.50 and 0.69 ; low positive (or negative) when between 0.30 and 0.49 ; and negligible correlation when less than $0.30 .{ }^{21}$ The $p$ values of 0.01 and 0.05 were taken as the reference level of significance. Due to the transformation of WOSI-PT to 100 , ranging from "0 = Worst" to "100 = Best", as suggested by Angst et al, ${ }^{14}$ a negative correlation with QuickDASH is expected, and a positive one with SF-12.

Statistical analyses were performed using the Statistical Package for Social Sciences Software (SPSS) version 24.0 (IBM Corporation, Chicago, IL, USA).

\section{RESULTS}

\section{Cross-cultural adaptation}

Some differences in sentence composition were found between the two translation versions. After the first consensus panel discussion, the translated version of WOSI was finalized. The back translation was then carried out and two back-translated versions were produced. Both were confirmed to have retained the questionnaire's original meaning. Turning to the process undertaken by the expert committee, the meaning of the words and expressions 'snapping', 'looseness', 'How much loss', and 'How much do you feel' in Portuguese were discussed, and words or expressions were selected that fit better with the original questions. As there were minor aspects in the comprehensibility test that were 'not well understood', they were replaced by other words within the same context. This version was again applied to 10 other participants, and, as there were no significant changes in the structure and evaluation properties, this final version was used for the validation study (WOSI-PT). Therefore, this version was used in the validation study without any additional modification, and no item was left blank.

\section{Validation study}

Demographic and disease-descriptive characteristics of patients are presented in Table 1. A total of 81 patients with clinical diagnosis of shoulder instability were included in the internal consistency and validity assessments, and 50 of them were randomly selected and included in the reproducibility and measurement error assessment. There were no missing data for any individual items on the WOSI-PT, QuickDASH, or SF-12.

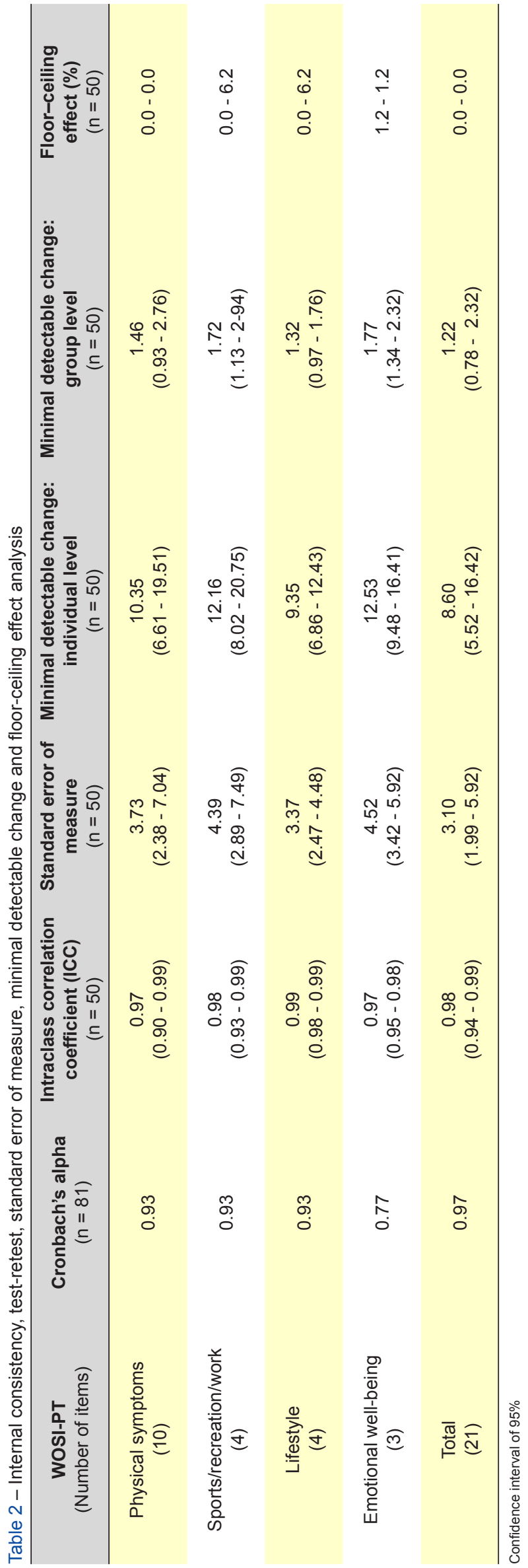




\section{Reliability and sensitivity}

The results of internal consistency, reproducibility, as well as standard error of measure, minimal detectable change (individual and group levels), and the floor and ceiling effects are presented in Table 2. Cronbach's alpha coefficient (0.97) indicates a high level of internal consistency in the WOSI-PT questionnaire. When analyzing Cronbach's alpha coefficient for each domain, 'emotional well-being' had the least internal consistency (0.77). Nevertheless, this value was still not found to be below the cut-off value.

The test-retest analysis of the total score of the WOSIPT showed very high ICC (0.98). In the same manner, high ICC values were verified in 'physical symptoms', 'sports/ recreation/work', 'life-style', and 'emotional well-being', ranging from $0.97-0.99$. Therefore, the WOSI-PT, as well as each domain, are stable over time. Additionally, the SEM recorded was 3.1 points, and the minimal detectable change at individual and group levels was 8.60 and 1.22 points, respectively.

Regarding to the floor-ceiling effects, the analysis of the worst-best status values revealed no floor-ceiling effect (less than 15\%) [29] in total score $(0 \%)$ nor in the different modules $(0-6.2 \%)$.

\section{Construct validity}

In order to analyse the convergent validity, a correlation analysis of WOSI-PT with QuickDASH and SF-12 questionnaires was conducted (Table 3).

The total score of WOSI-PT had a high negative correlation with the total score of QuickDASH (-0.798), as did WOSI-PT with the module 'work' in QuickDASH (-0.733); while the correlation between WOSI-PT and the module 'sports' in QuickDASH was positive and moderate (0.544). Moreover, a good correlation was found between WOSI-PT and the Physical component of SF-12 (0.666), and a moderate correlation was found between WOSI-PT and the mental component of SF-12 (0.354).

\section{DISCUSSION}

The aim of this study was to translate and culturally adapt the WOSI Index into European Portuguese and to verify its reliability and validity.

The WOSI questionnaire is an instrument to specifically measure functionality and the impact of shoulder instability on quality of life, in contrast with other validated scales for the Portuguese population which are not specific for shoulder instability. Therefore, it was important to have a tool to determine, for example, the effect of treatment on shoulder instability and/or the impact of this disorder on quality of daily life. The results of the present study showed that WOSI-PT is a reliable and valid instrument; consequently, it can be used for this specific shoulder disability, thus fulfilling the purposes of the original version.

In fact, the Cronbach's alpha analysis showed a high level of internal consistency in the WOSI-PT. The value of 0.97 was comparable to that of other validation studies. ${ }^{1,3,6,12}$ The extremely high value of Cronbach's alpha suggests that the Portuguese version of WOSI could have certain items with some redundancy. However, when analyzing the four different domains of WOSI-PT, the Cronbach's alpha ranged from 0.77 to 0.93 , confirming the good consistency of each domain of the scale. In examining the internal consistency of WOSI validated for other countries, a Cronbach's alpha of 0.91 in the Turkish version, ${ }^{3} 0.92$ in the Dutch version, ${ }^{22}$ and 0.95 in the Sweden version ${ }^{12}$ were found.

The results also demonstrated excellent reproducibility for the WOSI-PT, with an ICC of 0.98 (IC 0.94 - 0.99), and all four domains ranged from 0.97 to 0.99 , being in agreement with several other WOSI validations. ${ }^{3,12,22}$

Our results recorded a SEM of $3.1 \%$ (65 out of 2100 points) and an MDC of $8.6 \%$ (180 out of 2100 points), for a 72 hours interval, indicating that an improvement in the WOSI-PT of at least 181 points between two different assessment moments could be considered significant, independently of measurement error. These results agreed with several others, such as those found by Cacchio et al (2012) (SEM of $3.4 \%$ and MDC $95 \%$ of $9.3 \%$ ), ${ }^{23}$ Van der Linde et al (SEM of $8.3 \%$ and MDC $95 \%$ of $23 \%$ ), ${ }^{24}$ and Wiertsema et al (SEM of $6.2 \%$ and MDC95\% of $17.2 \%) .{ }^{22}$

Descriptive statistical analysis showed that there are no floor nor ceiling effects in the WOSI-PT ( $n$ 81 0-0\%). According to Arafat et al. (2016), ${ }^{25}$ the floor-ceiling effect is present when over $15 \%$ of the subjects obtained the lowest or highest possible scores on the scale, which indicates the proportion for whom no meaningful deterioration or improvement in their condition could be detected since they are already at the extreme of the range. Therefore, it is possible to determine changes in the clinical conditions of

Table 3 - Spearman correlation analysis of WOSI-PT with QuickDASH and SF-12 questionnaires

\begin{tabular}{|c|c|c|c|c|c|}
\hline \multirow{2}{*}{ WOSI-PT } & \multicolumn{2}{|c|}{ QuickDASH } & SF-12 & \multirow[b]{2}{*}{ Physical } & \multirow[b]{2}{*}{ Mental } \\
\hline & Total & Work & Sports & & \\
\hline Physical symptoms & $-0.768^{* *}$ & $-0.738 * *$ & $-0.489^{*}$ & $0.631^{* *}$ & $0.347^{*}$ \\
\hline Sports/recreation/work & $-0.794^{* *}$ & $-0.758^{* *}$ & $-0.638^{* *}$ & $0.681^{* *}$ & $0.364^{* *}$ \\
\hline Lifestyle & $-0.761^{* *}$ & $-0.709 * *$ & $-0.453^{*}$ & $0.654^{* *}$ & $0.339 *$ \\
\hline Emotional well-being & $-0.541^{* *}$ & $-0.374^{*}$ & $-0.532^{* *}$ & $0.379 * *$ & $0.262^{*}$ \\
\hline Total & $-0.798^{* *}$ & $-0.733^{* *}$ & $-0.544^{* *}$ & $0.666^{* *}$ & $0.354^{* *}$ \\
\hline
\end{tabular}

WOSI -PT: Western Ontario Shoulder Instability index of the Portuguese version; QuickDash: The Quick Disabilities of the Arm, Shoulder and Hand score; SF-12: Short Form 12 Health Survey

*: correlation is significant at $p<0.05 ; * *$ : correlation is significant at $p<0.01$ 
patients more precisely.

Regarding validity, the WOSI-PT reported a high negative correlation (- 0.798) with QuickDASH, which is in agreement with results found in the validation process for the Turkish $(0.67)^{3}$ and Dutch (0.81) versions. ${ }^{22}$ It is important to stress that both WOSI-PT and QuickDASH scored "0" as 'no limitations'. Nevertheless, the negative correlation in our study is attributed to the inversion of the scale.

After analyzing the correlations between the domains of WOSI-PT and QuickDASH, high negative correlations with 'physical symptoms' (-0.768), 'sports/recreation/work' $(-0.794)$, and 'life-style' (-0.761) were found; in contrast, the correlation of the WOSI 'emotional well-being' domain with QuickDASH showed a moderate negative correlation (- 0.541).

The physical and mental components of SF-12 were also correlated with WOSI-PT, and a moderate positive correlation was found for the Physical component (0.666); as expected, a low positive correlation with the mental component (0.354) was found.

One limitation of our study was the fact that the responsiveness analysis, which is important to understand the sensitivity of the scale to detect clinically important changes over time, was not executed, even when the changes were small.

\section{CONCLUSION}

The Portuguese version of WOSI questionnaire is a reliable and valid tool to measure shoulder-related quality of life in patients with symptomatic shoulder instability.

\section{REFERENCES}

1. Hatta T, Shinozaki N, Omi R, Sano H, Yamamoto N, Ando A, et al. Reliability and validity of the Western Ontario Shoulder Instability index (WOSI) in the Japanese population. J Orthop Sci. 2011;16:732-6.

2. Olds M, Ellis R, Donaldson K, Parmar P, Kersten P. Risk factors which predispose first-time traumatic anterior shoulder dislocations to recurrent instability in adults: a systematic review and meta-analysis. $\mathrm{Br} \mathrm{J}$ Sports Med. 2015;49:913-22.

3. Basar S, Gunaydin G, Hazar K, Sozlu U, Alkan Z, Pala O, et al. Western Ontario Shoulder Instability index: cross-cultural adaptation and validation of the Turkish version. Rheumatol Int. 2017;37:1559-65.

4. Torrance E, Clarke C, Monga P, Funk L, Walton M. Recurrence after arthroscopic labral repair for traumatic anterior instability in adolescent rugby and contact athletes. Am J Sports Med. 2018;46:2969-74.

5. Nassiri N, Eliasberg C, Jones K, McAllister D, Petrigliano F. Shoulder instability in the overhead athlete: a systematic review comparing arthroscopic and open stabilization procedures. Orthop J Sports Med. 2015;3:S1-2.

6. Perrin C, Khiami F, Beguin L, Calmels P, Gresta G, Edouard P. Translation and validation of the French version of the Western Ontario Shoulder Instability index. Orthop Traumatol Surg Res. 2017;103:141-9.

7. Yuguero M, Huguet J, Griffin S, Sirvent E, Marcano F, Balaguer M, et al. Transcultural adaptation, validation and assessment of the psychometric properties of the spanish version of the Western Ontario Shoulder Instability index questionnaire. Rev Esp Cirug Ortoped Traumatol. 2016;60:335-45.

8. Barbosa G, Leme L, Saccol M, Pocchini A, Ejnisman B, Griffin S. Tradução e adaptação cultural para o português do Brasil do western ontario shoulder instability index (WOSI). Bras Med Esporte. 2012;18:357.

9. Breckenridge JD, McAuley JH. Shoulder Pain and Disability Index (SPADI). J Physiother. 2011;57:197.

10. Santos J, Gonçalves RS. Adaptação e validação cultural da versão portuguesa do Disabilities of the Arm Shoulder and Hand-DASH. Rev

\section{AUTHORS CONTRIBUTION}

All the authors had an equal contribution to the literature research, draft and distribution of the questionnaire, analysis of the results and draft of the paper.

\section{PROTECTION OF HUMANS AND ANIMALS}

The authors declare that the procedures were followed according to the regulations established by the Clinical Research and Ethics Committee and to the Helsinki Declaration of the World Medical Association updated in 2013.

\section{DATA CONFIDENTIALITY}

The authors declare having followed the protocols in use at their working center regarding patients' data publication.

\section{COMPETING INTERESTS}

The authors have declared that no competing interests exist nor any form of support.

\section{INFORMED CONSENT}

Informed consent was obtained from all patients included in the study.

\section{FUNDING SOURCES}

This research received no specific grant from any funding agency in the public, commercial, or not-for-profit sectors.

Port Ortoped Traumatol. 2006;14:29-44.

11. Kirkley A, Griffin S, McLintock H, Ng L. The development and evaluation of a disease-specific quality of life measurement tool for shoulder instability. The Western Ontario Shoulder Instability index (WOSI). Am J Sports Med. 1998;26:764-772.

12. Salomonsson B, Ahlström S, Dalén N, Lillkrona U. The Western Ontario Shoulder Instability index (WOSI): validity, reliability, and responsiveness retested with a Swedish translation. Acta Orthop. 2009;80:233-8.

13. Rouleau DM, Faber K, MacDermid JC. Systematic review of patientadministered shoulder functional scores on instability. J Shoulder Elbow Surg. 2010;19:1121-8.

14. Angst F, Schwyzer H, Aeschlimann A, Simmen B, Goldhahn J, Angst $F$, et al. Measures of adult shoulder function: Disabilities of the Arm, Shoulder, and Hand questionnaire (DASH) and its short version (QuickDASH), Shoulder Pain and Disability index (SPADI), American Shoulder and Elbow Surgeons (ASES) Society standardized shoulder assessment form, Constant (Murley) Score (CS), Simple Shoulder test (SST), Oxford Shoulder score (OSS), Shoulder Disability questionnaire (SDQ), and Western Ontario Shoulder Instability index (WOSI). Arthritis Care Res. 2011;63:174-188.

15. Reeve BB, Wyrwich KW, Wu AW, Velikova G, Terwee CB, Snyder CF, et al. ISOQOL recommends minimum standards for patient-reported outcome measures used in patient-centered outcomes and comparative effectiveness research. Qual Life Res. 2013;22:1889-905

16. Mokkink LB, Boers M, van der Vleuten CP, Bouter LM, Alonso J, Patrick $\mathrm{DL}$, et al. COSMIN risk of bias tool to assess the quality of studies on reliability or measurement error of outcome measurement instruments: a Delphi study. BMC Med Res Methodol. 2020;20:293.

17. Lu M, Zhong W, Liu Y, Miao H, Li Y, Ji M. Sample size for assessing agreement between two methods of measurement by Bland-Altman method. Int J Biostat. 2016;12:20150039.

18. Beaton DE, Wright JG, Katz JN. Development of the QuickDASH: comparison of three item-reduction approaches. J Bone Joint Surg Am. 
2005:87:1038-46

19. Ware J, Kosinski M, Keller SD. A 12-Item short-form health Survey: construction of scales and preliminary tests of reliability and validity. Med Care. 1996;34:220-33.

20. Ferreira PL. Criação da versão portuguesa do MOS SF-36. Parte II Testes de validação. Acta Med Port. 2000;13:119-127.

21. Mukaka MM. Statistics corner: a guide to appropriate use of correlation coefficient in medical research. Malawi Med J. 2012;24:69-71.

22. Wiertsema S, Rietberg M, Hekman K, Schothorst M, de Witte P, Steultjens $\mathrm{M}$, et al. Measurement properties of the Dutch version of the Western Ontario Shoulder Instability index (WOSI). J Orthop Sci. 2014;19:242-9.
23. Cacchio A, Paoloni M, Griffin SH, Rosa F, Properzi G, Padua L, et al. Cross-cultural adaptation and measurement properties of an Italian version of the Western Ontario Shoulder Instability index (WOSI). J Orthop Sports Phys Ther. 2012;42:559-67.

24. van der Linde J, van Kampen D, van Beers L, van Deurzen D, Saris D, Terwee C. The responsiveness and minimal important change of the Western Ontario Shoulder Instability index and Oxford Shoulder Instability score. J Orthop Sports Phys Ther. 2017;47:402-10.

25. Arafat S, Chowdhury H, Qusar M, Hafez M. Cross-cultural adaptation and psychometric validation of research instruments: a methodological review. J Behav Health. 2016;5:129-36. 